\title{
Evaluation of the effects of underlying surface change on catchment hydrological response using the HEC-HMS model
}

\author{
CHENG YAO ${ }^{1}$, LU CHANG ${ }^{2}$, JIE DING ${ }^{3}$, ZHIJIA LI ${ }^{1}$, DONG AN ${ }^{1}$ \\ \& YUXIA ZHANG ${ }^{1}$ \\ 1 College of Hydrology and Water Resources, Hohai University, Nanjing 210098, China \\ yaocheng@hhu.edu.cn \\ 2 Wuxi Water Resources Bureau, Wuxi 214002, China \\ 3 Institute of Water Resources Management, Hydrology and Agricultural Hydraulic Engineering, Leibniz University \\ Hannover, Hannover D-30060, Germany
}

\begin{abstract}
Due to rapid population growth, China, and urbanization, the Dongwan catchment, with a drainage area of $2856 \mathrm{~km}^{2}$ and located in Henan Province, has been subjected to considerable land-use changes since the 1990s. Distributed or semi-distributed models have been widely used in catchment hydrological modeling, along with the rapid development of computer and GIS technologies. The objective of this study is to assess the impact of underlying surface change on catchment hydrological response using the Hydrologic Engineering Center's Hydrologic Modeling System (HEC-HMS), which is a distributed hydrological model. Specifically, 21 flood events were selected for calibrating and validating the model parameters. The satisfactory results show that the HEC-HMS model can be used to simulate the rainfall-runoff response in the Dongwan catchment. In light of the analyses of simulation results, it is shown that the flood peaks and runoff yields after 1990 moderately decrease in comparison with that before 1990 at the same precipitation level. It is also indicated that the underlying surface change leads to the increased flood storage capacity after 1990 in this region.
\end{abstract}

Key words HEC model; change of underlying surface; rainfall-runoff response; Dongwan catchment; hydrological model

\section{INTRODUCTION}

Landscape and water resource management are major challenges for the socio-economic development of upland catchments in China due to their association with downstream environmental impacts and water supply. During recent decades, concerns about the impacts of changing patterns of land use associated with deforestation and agricultural transformation on water resources have created social and political tensions from local to national levels. Major concerns focus on consequences of land-use change for local and downstream hydrological hazards, for water supply and demand, and for biodiversity conservation (Thanapakpawin et al. 2006). Forecasting the spatial distribution of water availability requires hydrologic modelling of it. In growing areas, one of the primary factors that cause changes in water resources is the constant evolution in land use (Wijesekara et al.2012). Recent studies demonstrated the potential of an integrated modelling approach to evaluate the impact of land-use changes on water resources (Bithell and Brasington 2009).

Experimental catchment and representative catchment approaches are widely used to analyse the hydrological effects of spatial variability of the underlying surface on catchment response (Chow et al. 1988). The experimental catchment approach was developed in the 1930s abroad, and then in the 1950s China started to set up runoff experiment stations on a large scale and do a lot of research. The concept of the representative catchment as a hydrologically similar catchment (USACE-HEC 2000) was brought forward in the International Hydrological Decade. Since the 1960s, with the rapid development of computer science and spatial survey technology, the progress made in hydrological models has provided an effective way to analyse hydrological effects of land surface change. Based on the understanding of hydrological processes, hydrological models can be used to assess the relationships of different elements, simulate catchment hydrological response through mathematical methods, and make better use of GIS and RS technologies to evaluate the effects of the uneven spatial distribution characteristics of the precipitation and underlying surface.

In this paper, the HEC-HMS model is applied to the Dongwan catchment, which is regarded as a representative catchment, to evaluate the impact of land cover/land-use change on hydrological response. The model is firstly calibrated and verified by the use of available streamflow data for 
different years with stable underlying surface conditions. Then, the calibrated model is used to simulate the rainfall-runoff processes within the Dongwan catchment for the change period in which performance is assessed by comparing simulated and observed flows. And last, the results are statistically analysed to quantify the effects of underlying surface change on total runoff volume and peak flows.

\section{HEC-HMS MODEL DESCRIPTION}

HEC-HMS, i.e. the US Army Corps of Engineers' Hydrologic Modeling System computer program, can be used to simulate the rainfall-runoff and routing processes. It consists of the Basin Model, the Meteorological Model and the Control Specifications (USACE-HEC 2000, 2001). The Basin Model is used to construct hydrological models over the whole hydrological system, including computing runoff volume, modelling direct runoff, base flow and channel flow, and calibrating the HEC-HMS model parameters. The Meteorological Model is mainly used to input and manage rainfall data, by describing the distribution of precipitation stations, analysing station weights, and computing the average rainfall of the basin. The Control Specifications is to set start time and end time and then simulate the catchment runoff process. In the simple conceptualization of the catchment runoff process, precipitation falls on either the water surface or the land surface. Some precipitation on the water surface totally turns into overland flow and moves to the channel; some precipitation on land surface after subtracting a portion for evaporation, plant interception depression storage and infiltration, turns into overland flow and interflow and then moves to the stream channel. The stream channel is a combination point for the overland flow, the interflow and the base flow. The HEC model does not describe how the infiltrated water moves horizontally in the soil layers in detail or simulate groundwater movement, just treating the shallow interflow and the overland flow as direct runoff and groundwater as the base flow (USACE-HEC 2000).

According to catchment characteristics and the available information, the appropriate models adopted in this paper include the SCS curve number (SCS-CN) model for runoff yield, Snyder's UH model for direct runoff, Exponential recession model for base flow, and Muskingum routing model for channel flow. The HEC-HMS model pre-sets different initial values for parameters of each subbasin according to their various conditions, and optimises them by the trial-and-error method until the values are up to the required standard (Diskin and Simon 1977).

The SCS curve number model computes runoff by empirical rainfall-runoff relationships. The curve number $C N$ for a catchment can be estimated as a function of land use, soil type, and antecedent catchment moisture, shown in tables published by the SCS. This model considers the land surface condition, such as soil condition, terrain, and land use, and can reflect the impact of human activities on runoff processes. Excess precipitation is estimated using the following equation:

$$
P_{t}=\left(P-I_{a}\right)^{2} /\left(P-I_{a}+S\right)
$$

where $P_{t}$ is the accumulated excess precipitation at time $t, P$ is the accumulated rainfall depth at time $t$, and $S$ is the potential maximum retention. $S$ and $I_{a}$, the soil moisture deficit, can be determined by the relationships with $C N$ (Ponce and Hawkins 1996). $C N$ values range from 0 to 99, but generally no less than 40 (Scharffenberg et al. 2003). This model is especially suited to runoff simulation in smaller basins, with areas no more than $8 \mathrm{~km}^{2}$.

Snyder's UH model is an empirical model of the relationship of direct runoff to excess precipitation (Loague and Freeze 1985, Kull and Feldman 1998). The parameters, Snyder lag time $T_{p}$ and Snyder peaking coefficient $C_{p}$, need to be calibrated beforehand when using the HEC-HMS model to derive flood hydrographs. The relationship between $T_{p}$ and $C_{t}$ is given by:

$$
T_{p}=C_{t}\left(L L_{c}\right)^{0.3}
$$

where $L$ is the length of the main stream, $L_{c}$ is the distance along the main stream from the catchment centre to its outlet, and $C_{t}$ is the UH lag coefficient.

The Exponential Recession model is used to simulate catchment baseflow. It has often been used to explain the drainage from natural storage in a catchment (USACE-HEC 2000). The 
Muskingum routing method is based on the assumption of a linear relationship between the inflow to and the outflow from a river reach and the reach storage. By ignoring the inertial term, the St. Venant equations are simplified into the diffusion equations, the dynamic wave evolving into the diffusion wave. The Muskingum method is widely used for relatively steep channels with little floodplain storage, usually in natural channels where downstream backwater has little effect (Stephenson 1979).

\section{CALIBRATION AND APPLICATION OF HEC-HMS MODEL}

\section{Dongwan catchment and data description}

The Dongwan catchment is located in Henan Province, China, between longitudes $111^{\circ}-112^{\circ} \mathrm{E}$ and latitudes $33.5^{\circ}-34.5^{\circ} \mathrm{N}$, with a drainage area of $2856 \mathrm{~km}^{2}$. It is a major upper tributary sub-basin of the Yihe River, which in turn is a large tributary of the Yellow River. The altitude increases gradually from the east to the west; there is a large area of forest land in the upstream region. The average annual temperature ranges from 12 to $14^{\circ} \mathrm{C}$. The spatial distribution of rainfall varies widely from year to year, as affected by the continental monsoon climate. The annual rainfall increases with the elevation, the rainfall in the mountainous area is more than that in the plain area. Moreover, the annual rainfall varies so significantly that the maximum value is almost twice as large as the minimum value in this catchment. In each year, the rainfall amount from July to September is more than $50 \%$ of the annual precipitation.

Observations of 21 flood events from 1964 to 2000 were selected for the model calibration and validation at the hourly time step. The digital elevation model (DEM) on a grid scale of $1 \mathrm{~km}\left(30^{\prime \prime}\right)$ obtained from USGS was used to derive topographic attributes of the catchment. The Dongwan catchment was divided by means of HEC-GeoHMS (USACE-HEC 2001) into 20 smaller sub-basins to account for spatial variability of terrain and precipitation. The area proportions of these sub-basins range from $0.9 \%$ to $12.7 \%$. The drainage network and the delineated sub-basins of the study catchment are shown in Fig. 1.

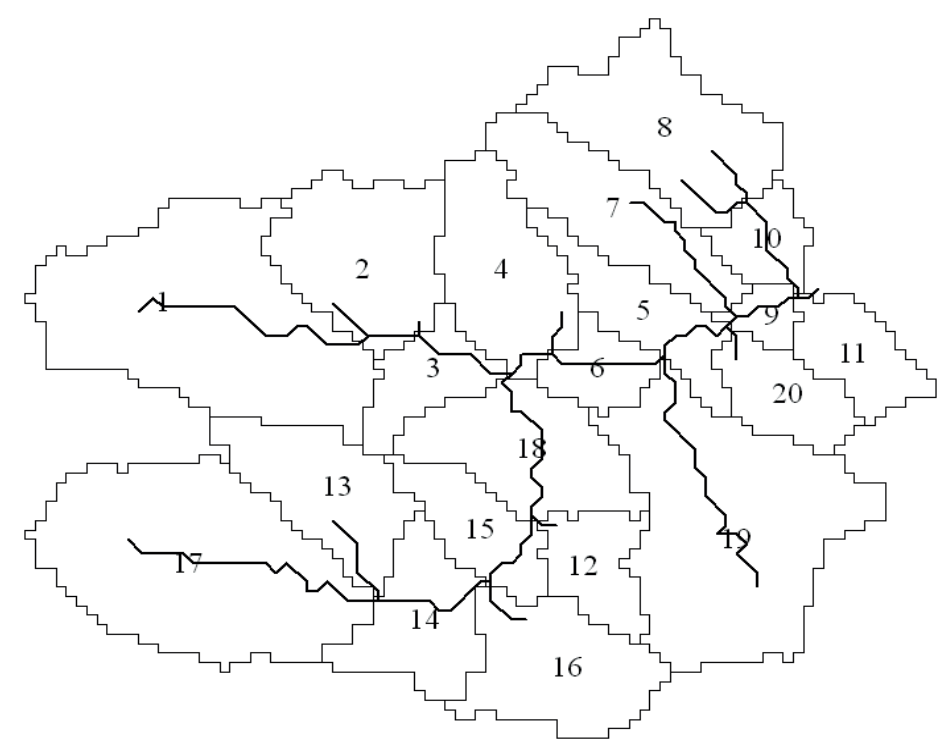

Fig. 1 Drainage network and delineated sub-basins of the Dongwan catchment.

\section{Parameter calibration}

The HEC-HMS model usually exhibits better performance when simulating high-volume or singlepeak flood events. However, the simulations for low-volume or multi-peak flood events are relatively poor; the differences in peak time between simulations and observations are generally large for double-peak events. As the model is sensitive to rainfall data, the simulated streamflow 
hydrographs may still vary significantly, even in the case of slight variation of rainfall. Therefore, the computational time interval for model simulation should not be too long. It is particularly important to derive reasonable values of the parameters in model application for reducing errors caused by model inadequacy. In terms of the analysis of series of measured precipitation, pan evaporation and streamflow data, observations for calibration were separated into two periods: the period 1960-1989 and the period 1990-2000. The parameters of the HEC-HMS model were pre-set by referring to literature and calibrated using the trial-and-error method. Table 1 lists the calibrated values of the parameters for two split periods.

Table 1 The calibrated parameter values for the two periods.

\begin{tabular}{llll}
\hline Parameter & Description & $1960-1989$ & $1990-2000$ \\
\hline$C N$ & SCS curve number & 70 & 55 \\
$I_{m}$ & Impervious area proportion & 0.01 & 0.01 \\
$T_{p}$ & Snyder lag time & 3 & 5 \\
$C_{p}$ & Snyder peaking coefficient & 0.96 & 0.96 \\
$K$ & Recession constant of groundwater & 0.5 & 0.65 \\
$T_{f}$ & Threshold flow & 20 & 20 \\
$x$ & Muskingum weighting factor & 0.35 & 0.35 \\
\hline
\end{tabular}

\section{RESULTS AND DISCUSSION}

The used assessment criteria are relative runoff error (RRE, \%), relative peak error (RPE, \%) and Nash-Sutcliffe efficiency (NSE) (Nash and Sutcliffe 1970, Moriasi et al. 2007).

$$
\begin{aligned}
& R R E=\left(R_{\text {sim }}-R_{o b s}\right) / R_{o b s} \times 100 \% \\
& R P E=\left(Q_{\text {simp }}-Q_{o b s p}\right) / Q_{o b s p} \times 100 \% \\
& N S E=1-\sum_{t=1}^{z}\left[Q_{\text {sim }}^{t}-Q_{o b s}^{t}\right]^{2} / \sum_{t=1}^{z}\left[Q_{o b s}^{t}-\overline{Q_{o b s}}\right]^{2}
\end{aligned}
$$

where $R_{o b s}$ is the observed runoff volume, $R_{s i m}$ is the simulated runoff volume, $Q_{o b s p}$ is the observed peak discharge, $Q_{\text {simp }}$ is the simulated peak discharge, $Q_{\text {obs }}^{t}$ is the observed discharge for each time step $t, Q_{\text {sim }}^{t}$ is the simulated or predicted value at time $t, \overline{Q_{o b s}}$ is the observed mean within the time period of analysis, and $z$ is the total number of values.

The accuracy statistics for the Dongwan catchment during the period 1960-2000 are shown in Fig. 2(a). The top and bottom lines in Fig. 2(a) represent the maximum and minimum values, respectively, while the top, middle, and bottom of the box represent the 75th percentile, the median and the 25th percentile, respectively. According to the simulated results, the percentages of qualified simulations with respect to RPE and RRE are $90 \%$ and $86 \%$, respectively, while the absolute means of RPE and RRE are $9.1 \%$ and $9.6 \%$, respectively. The average value of NSE is 0.87 ; the NSE values of 11 flood events are greater than 0.90 , which indicates that the simulated flood hydrographs are conceptually reasonable for the HEC-HMS model applied to the study catchment. Looking collectively at the simulation results, the output of the model is satisfactory when making use of the split parameter value groups.

Figure 2(b) shows the RPE and RRE accuracy statistics for the period 1990-2000 (used as validation period) using calibrated parameter values for the period 1960-1989 (used as calibration period). As seen from this figure, the flood peaks and runoffs were overestimated for all events in this case; the means of RPE and RRE are $13.1 \%$ and $35.1 \%$, respectively. Similarly, for the period 1960-1989, the RPE and RRE accuracy statistics using the parameter values for the period 19902000 are displayed in Fig. 2(c). The means of RPE and RRE are $-15.4 \%$ and $-19.5 \%$, respectively. The results in both cases indicate that, at the same precipitation level, the peaks and runoff 

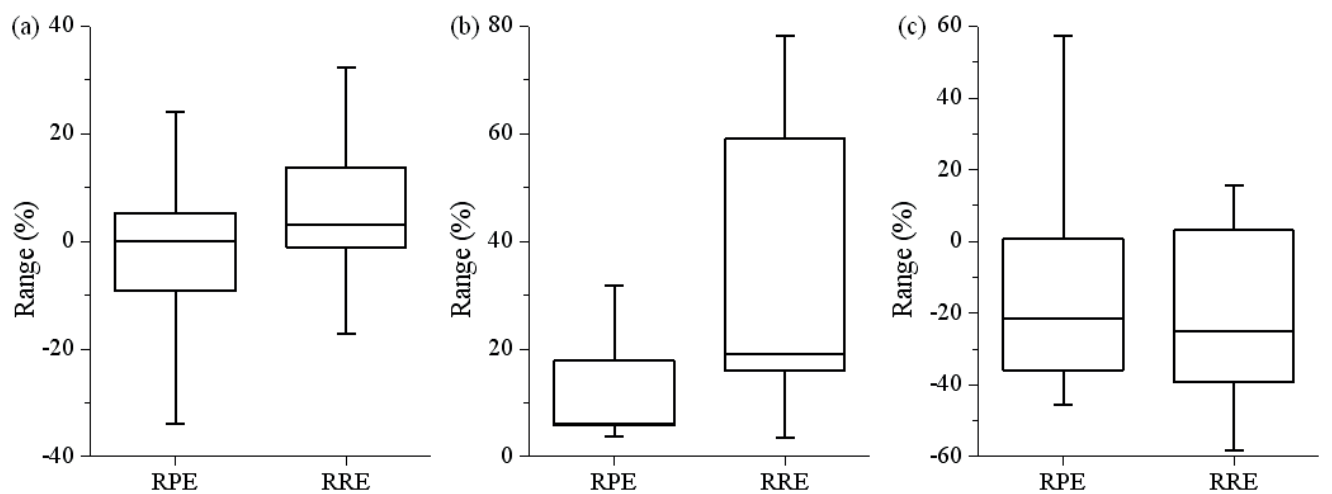

Fig. 2 Boxplots of RPE and RRE accuracy statistics for: (a) the period 1960-2000 using two split parameter value groups, (b) the period 1990-2000 using the parameter values for the period 1960-1989, and (c) the period 1960-1989 using the parameter values for the period 1990-2000.

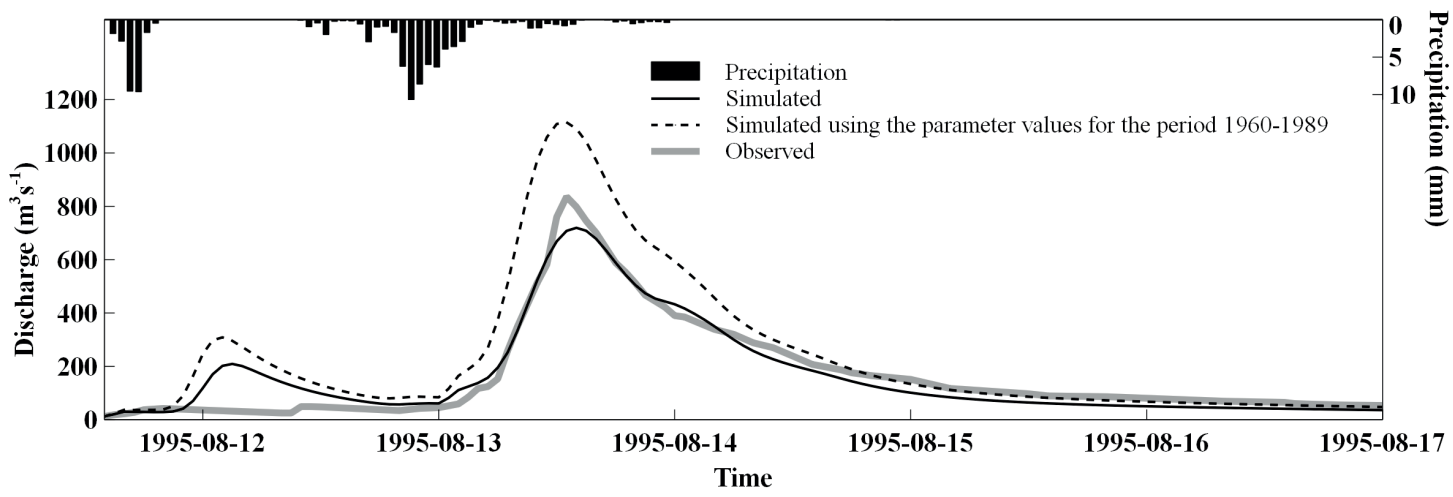

Fig. 3 Example (11 August 1995-17 August 1995) of observed hydrograph and simulated hydrographs using the parameter values for the period 1990-2000 (black line) and the period 1960-1989 (dotted line), respectively

volumes after 1990 moderately decrease in comparison with those before 1990. As an example, Fig. 3 illustrates the comparison of observed and simulated hydrographs for the flood event of August 1995. It can be seen that both the peak and runoff volume of this event were overestimated when using the parameter values for the period 1960-1989. The most probable cause may be the effects of underlying surface change.

In light of the parameter values listed in Table 1, the values of three parameters, including $C N$, $T_{p}$ and $K$, are different between the two periods. Generally, the three parameters are associated with runoff volumes, overland flow routing velocity and recession characteristics of groundwater outflow, respectively. The larger the value of $C N$, the more runoff volumes will be generated. Moreover, the smaller the values of $T_{p}$ and $K$, the slower responses of overland and groundwater flow to rainfall events will be probable. As seen from Table 1, the value of $C N$ for the former period (1960-1989) is larger than that for the latter period (1990-2000); the values of $T_{p}$ and $\mathrm{K}$ are smaller for the former. Hence, it can be proved that the capacities of runoff generation and flood storage of the region has decreased and increased, respectively, after 1990. Actually, these differences are coincident with the changes of underlying surface in this area. As different hydrologic response would be linked to observed changes in land use, it would be fairly good to describe the land-use changes with land-use maps from the two periods. However, land-use data obtained from different sources often varies significantly, and land-use data of the study area is also hard to get. From this point, making a brief and complete investigation is a better choice. During the 1960s to the 1980s, many projects, such as soil and water conservation, afforestation and vegetation restoration, and construction of small reservoirs, have been implemented in the study area. Since the beginning of the 1990s the government of Luanchuan County, in the upstream of the study basin, has constructed its timberland into the Dragon Island Bay National Forest Park as well as other nature tourist 
attractions. These projects can have a powerful impact on hydrological response and lead to the changes of runoff yields and flood storage capacity.

\section{CONCLUSIONS}

This paper presents the assessment of underlying surface change impacts on catchment hydrological response using the HEC-HMS model applied to the Dongwan catchment. The measured data sets of the catchment were separated into the two periods bounded by the year 1990. The results show that the model can be applied for flood simulation adequately when using two calibrated parameter value groups. In terms of cross-validation between the two groups, the tests indicate that the runoff yields and flood peaks under the same rainfall condition have a moderate decrease after 1990. Further analyses demonstrate that the most possible cause is the impacts of underlying surface change, which makes the runoff volumes decrease and flood storage capacity increase in this region.

Evaluating hydrological response to forecasted land-use change is a positive exercise. The simulated results provide important information for flood control plans for reservoirs located in the downstream of the Yihe River. According to recent literature (Eli and Lamont, 2010; Woodward et al. 2010), there are some limitations in using the SCS-CN method. Therefore, we plan to do more research in this area in our future work.

Acknowledgements This work was supported by the National Natural Science Foundation of China (grant nos. 41101017, 41130639, 51179045 and 41201028). Meteorological and streamflow data were kindly provided by the Dongwan River Basin Organization of the Yellow River Water Conservancy Committee. The authors would like to thank the anonymous reviewers for their valuable comments and suggestions.

\section{REFERENCES}

Bithell, M. and Brasington, J. (2009) Coupling Agent-based models of subsistence farming with individual-based forest models and dynamic models of water distribution. Environmental Modelling and Software, 24, 173-190.

Chow, V. T., Maidment, D. R. and Mays, L.W. (1988) Applied Hydrology. McGraw-Hill, New York.

Diskin, M. H. and Simon, E. (1977) A procedure for the selection of objective functions for hydrologic simulation models. Journal of Hydrology, 34, 129-149.

Eli, R. N. and Lamont, S. J. (2010) Curve numbers and urban runoff modeling-application limitations. In: Low Impact Development 2010: Redefining Water in the City, Proceedings of the 2010 International Low Impact Development Conference, 405-418.

Kull, D. and Feldman, A. (1998) Evolution of Clark’s Unit Graph Method to Spatially Distributed Runoff, Journal of Hydrologic Engineering ASCE 3, 9-19.

Loague, K. M. and Freeze, R. A. (1985) A comparison of rainfall-runoff modeling techniques on small upland catchments. Water Resources Research AGU 21, 229-248.

Moriasi, D., et al. (2007) Model evaluation guidelines for systematic quantification of accuracy in catchment simulations. Transactions of the ASABE 50, 885-900.

Nash, J. E. and Sutcliffe, J. V. (1970) River flow forecasting through conceptual models part i: a discussion of principles. Journal of Hydrology 10, 282-290.

Ponce, V. M. and Hawkins, R. H. (1996) Runoff curve number: has it reached maturity. Journal of Hydrologic Engineering ASCE $1,11-19$.

Scharffenberg, W., Fleming, M. and Feldman, A. (2003) The Hydrologic Modeling System (HEC-HMS): toward a complete framework for hydrologic engineering. World Water and Environmental Resources Congress 23-26, 1197-1204.

Stephenson, D. (1979) Direct optimization of Muskingum routing coefficients. Journal of Hydrology 41, 161-165.

Thanapakpawin, P., et al. (2006) Effects of land use change on the hydrologic regime of the Mae Chaem River Basin, NW Thailand. Journal of Hydrology 334, 215-230.

USACE-HEC (2000) Hydrologic Modelling System HEC-HMS, Technical Reference Manual. US Army Corps of Engineers, Hydrologic Engineering Center, Davis, California.

USACE-HEC (2001) Hydrologic Modelling System HEC-HMS, User's Manual. US Army Corps of Engineers, Hydrologic Engineering Center, Davis, California.

Wijesekara, G., et al. (2012) Impact of land-use changes on the hydrological processes in the Elbow River Catchment in Southern Alberta. International Congress on Environmental Modelling and Software 412-413, 220-232.

Woodward, D. E, et al. (2010) Discussion of "Modifications to SCS-CN method for long-term hydrologic simulation" by K. Geetha, S. K. Mishra, T. I. Eldho, A. K. Rastogi, and R. P. Pandey. Journal of Irrigation and Drainage Engineering. 136(6), 444-446. 